\title{
THIAMINE - INDUCED FORMATION OF THE MONOPYRROLE MOIETY OF PRODIGIOSIN
}

\author{
Sanad B. AL-Arrji*
}

\author{
Zeena F.Ahmed**
}

Anas G. Abdul kareem***

\author{
Date of acceptance 18/6/2007
}

\begin{abstract}
:
Thiamine stimulates the production of a red pigment, which is chromatographically and spectrophotometrically identical to prodigiosin, by growing cultures of serratia marcescens mutant 9-3-3 . this mutant is blocked in the formation of 2- methyl -3- amyl pyrorol( MAP), the monopyrrole moiety of prodigiosin , but accumulates 4-methoxy-2, 2bipyrrole -5- carboxaldehyde (MBC) and can couple this compound with( MAP) to form prodigiosin .

Addition of thiamine caused production of( MAP), and as little as $0.02 \mathrm{mg}$ of thiamine / $\mathrm{ml}$ in peptone- glycerol medium stimulated production of measurable amounts of prodigiosin. Phosphate saltes and another type of peptone decreased the thiamine- induced formation of prodigiosin ,yeast extract and glycerol enhanced formation of this substance.

Thiamine also enhanced production of prodigiosin by wiled - type Strain Nima of $S$. marcescens .

The pyrimidine moiety of thiamine was also $10 \%$ as effective as the vitamin ; the thiazol moiety only $4 \%$, and the two moieties together, $25 \%$.

Thiamine did not stimulate production of prodigiosin biosynthesis as strain 9-3-3 .

This is not surprising since strain 9-3-3 originated as a result of two mutational events one event may involve thiamine directly, and the other may involve the biosynthesis of( MAP).
\end{abstract}

\section{INTRODUCTION:}

Prodigiosin, the red pigment of serratia marcescens has been characterized as atripyrryl methane although this structure has never been confirmed by synthesis [11].

Prodigiosin is separated into four fraction : one blue, two red, and one orange, the blue fraction has not been reported previously [18].

Its produced by $\mathrm{S}$ marcescens, pseudomonas magnesiorubra,Vibrio psychroerythrus and other bacteria [6 ] [14 ].

Microscopic observation of S marcescens colonies showed that Prodigiosin pigment was localized in vesicles (extra cellular and cell associated ) or intercellular granules [9] [12 ]. this pigment is synthesized in a bifurcated pathway, in which mono-end bipyrrole precursors are synthesized separately and then coupled to form prodigiosin.

\section{AIM OF THE STUDY :}

This study aimed for detection prodigiosin which is produced from bacteria $S$ marcescens and the role of thiamine to induced this pigment .

\section{MATERAIL AND METHODS: ORGANISMS :}

Strains of serratia marcescens use in this investigation were :

1. Nima, Atypical ,wild-type strain that produces prodigiosin[18 ].

\footnotetext{
*Assist. Prof. College of Health \& Medical Technology

**Assist. Lecturer College of Health \& Medical Technology

***Assist. Lecturer Baghdad Oil Institute
} 
2. Mutan WF [2 ] [19 ] which produces 2- methyl -3- amyl pyrorol( MAP)but is blocked in synthesis of 4-methoxy-2, 2bipyrrole -5- carboxaldehyde (MBC) , and yet can couple these two moieties to form prodigiosin [3 ] [ 13 ] .

3. Mutan 9-3-3 [2 ] which extract MBC and also produces the enzyme for terminal biosynthesis of prodigiosin but is blocked in synthesis of MAP [ 15 ] .

4. Mutan H - 262 , which is phenotypically like strain 9-3-3 .

\section{MEDIA:}

The organism were maintained in stock on slants containing $2.5 \%$ agar , $0.5 \%$ peptone (difco) end either $0.5 \% L$ - prolin or $1.0 \%$ glycerol .

Liquid media used for quantitative experiments were :

1. PG, a medium containing $0.5 \%$ peptone and $1.0 \%$ glycerol in distilled water [ 5] .

2. MM , the minimal medium of Bunting [5].

3. $\mathrm{CM}$,a complete medium [ 18 ] made by adding $0.1 \%$ yeast extract (difco) and $0.2 \% \mathrm{~N}-\mathrm{Z}$ case peptone to MM medium .

4. SM , synthesis medium [ 7 ] containing distilled water $0.7 \%$ K2HPO4, $0.3 \% \quad \mathrm{KH} 2 \quad \mathrm{PO} 4, \quad 0.05 \%$ $\mathrm{Na} 3 \mathrm{C} 2 \mathrm{H} 2 \mathrm{O} 7.2 \mathrm{H} 2 \mathrm{O}, 0.01 \% \quad \mathrm{MgSO} 4$, $0.1 \%$ (NH4)2SO4 and $0.2 \%$ glucose that was autoclaved separately and added aseptically to the other ingredients after they had been autoclaved.

All media were adjusted to $\{\mathrm{pH} 7.2\}$ before autoclaving .

Thiamine and other test compounds were sterilized by filtration through membrane filters and then added to various media as indicated in the text cultures were grown in $250 \mathrm{ml}$ or liter Erlenmeyer flasks containing $200 \mathrm{ml}$ of liquid media .

\section{INCUBATION :}

All cultures were incubated aerobically at $27 C$. liquid cultures were shaken on a new bruns - wick rotary shaker ( model $G 26$ ) having a displacement of 1 inch \& rotating at 198 strokes/min .

\section{PIGMENT INTERMEDIATES AND CHEMICALS:}

The supernatant fluid from cultures of strain 9-3-3 grown for $24 \mathrm{hr}$ in PG medium was used as the source of MBC .

Cells were removed by centrifugation , and the supernatant fluid was sterilized by membrane filtration .

cultures of strain WF growing on PG agar were the source of the natural monopyrol, MAP [ 2] .

the commercial compounds were diluted in $0.05 \mu$ phosphate buffer, $\mathrm{pH} 6.8$, before sterilization.

\section{ANALYTICAL PROCEDURES:}

Protein was determined by the method of Lowry etal .[10 ] with bovine serum albumin as a standard .

The amount of MBC present was determined by first extracting the supernatant fluid with chloroform and determining spectrophotometrically the difference in absorption at 363 and $400 \mathrm{~nm}$ [16] .

This difference was proportional to amount of MBC in the supernatant fluid.

Prodigiosin and prodigiosin analogue were measured by extracting pigmented suspensions with acidic methanol and then measuring the difference in absorption of the extract at $534 \& 655 \mathrm{~nm}[18$ ] .

The same wave length could be used to measure both compounds a difference in absorbancy of 1.0 between the two wave lengths was equivalent to $19.3 \mu \mathrm{g}$ of prodigiosin or $17.2 \mu \mathrm{g}$ of prodigiosin analogue $1 \mathrm{mg}$ bacterial protein .

An indirect assay [ 17 ] was used to measure the volatile MAP because as yet no direct assay has been developed for this compound .

The indirect assay utilized the synthrophic interaction of mutant strain WF and 9-3-3 ; 
the volatile MAP produced by strain WF or by strain 9-3-3 when grown with thiamine, is coupled with the MBC synthesized by strain 9-3-3 to form prodigiosin . strain WF or strain 9-3-3 was grown on the appropriate test medium in the bottom of a Petridish, and strain 9-3-3 was spread uniformly over the surface of PG agar in the top of the same Petri dish. The amount of prodigiosin formed in the latter culture of strain 9-3-3, after incubation of the closed Petridish at $27 \mathrm{C}$ for $48 \mathrm{hr}$, was then measured by the procedure given above . one molecule each of MBC and MAP couple to form one molecule of prodigiosin.

\section{RESULTS:}

When thiamine was added to PG medium ,mutant strain 9-3-3 produced a red pigment $\{$ Fig 1$\}$

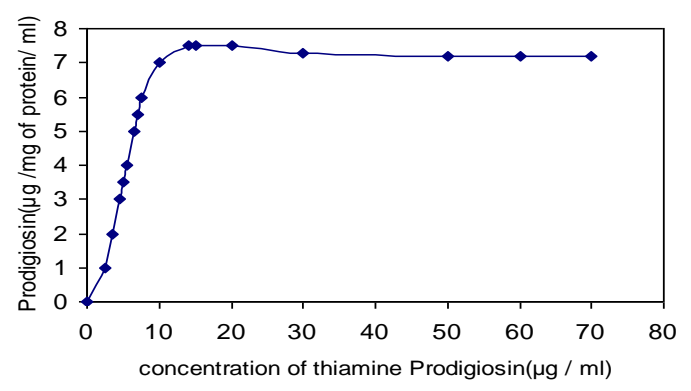

Fig (1) Effect of concentration of thiamine upon production of prodigiosin S marcescens strain9-3-3

Measurable amounts of pigment appeared at a thiamine concentration of $0.02 \mu \mathrm{g} / \mathrm{ml}$ of medium.

Up to a concentration of 10 to $14 \mu \mathrm{g}$ of thiamine/ $\mathrm{ml}$. the amount of pigment formed increased almost linearity (fig 1 ).

Higher concentration of the vitamin resulted in only slight increases in pigmentation .

As will be shown later, addition of thiamine to PG medium also enhanced production of prodigiosin by growing cultures of the wild - type strain,Nima
Addition of thiamine to other media also promoted formation of prodigiosin by strain 9-3-3 \{ Table $1 \& 2$ \}

Phosphate salts \{Table 1 \} and N-Z case peptone $\{$ Table 2 \} reduced the amount of prodigiosin formed even in the presence of thiamine . yeast extract and glycerol enhanced the effects of thiamine \{Table 2 \}.

In medium containing $100 \mu \mathrm{g}$ of thiamine / $\mathrm{ml}, 1.5 \%$ glycerol, and $0.2 \%$ yeast extract, almost $90 \mu \mathrm{g}$ of prodigiosin / mg of protein was formed a value that represented about 1 to $2 \%$ of the dry weight of cells .

Table 1: Production of prodigiosin by S. marcescens strain 9-3-3 when grown on various liquid media

\begin{tabular}{|c|c|}
\hline Medium & $\begin{array}{l}\operatorname{Prodigiosin}(\mu \mathrm{g} / \mathrm{mg} \\
\text { of protein/ ml })\end{array}$ \\
\hline $0.5 \%$ peptone \& $0.5 \%$ praline & 0.21 \\
\hline $\begin{array}{c}0.5 \% \text { peptone } \& 0.5 \% \text { praline plus } \\
\text { thiamine }\end{array}$ & 13.37 \\
\hline $0.5 \%$ peptone $\& 1.0 \%$ glycerol & 0.37 \\
\hline $\begin{array}{c}0.5 \% \text { peptone } \& 1.0 \% \text { glycerol plus } \\
\text { thiamine }\end{array}$ & 17.93 \\
\hline Minimal medium (MM) & 0.12 \\
\hline MM plus thiamine & 2.62 \\
\hline Complete medium $(\mathrm{CM})$ & 0.15 \\
\hline CM plus thiamine & 2.30 \\
\hline CM with phosphate salts omitted & 1.24 \\
\hline $\begin{array}{l}\text { CM with phosphate salts omitted plus } \\
\text { thiamine }\end{array}$ & 48.37 \\
\hline Synthetic medium (SM) & 0.23 \\
\hline SM plus thiamine & 1.91 \\
\hline $\begin{array}{l}\text { SM with low phosphate plus } 0.1 \% \text { tris- } \\
\text { (hydroxymethyl) minomethane } \\
\text { (Tris)buffer }\end{array}$ & 0.23 \\
\hline $\begin{array}{c}\text { SM with low phate plus } 0.1 \% \text { tris } \\
\text { buffer plus thiamine }\end{array}$ & 4.38 \\
\hline
\end{tabular}


Table 2: Effect of complex natural nutrients upon thiamin- inmduced formation of prodigiosin by $S$. arcescens strain 9-3-3

\begin{tabular}{|c|c|}
\hline Additions to basal medium & $\begin{array}{c}\text { Prodigiosin }(\mu \mathrm{g} \\
\text { /mg of protein/ } \\
\mathrm{ml})\end{array}$ \\
\hline $0.2 \%$ yeast extract & 1.35 \\
\hline $0.2 \%$ yeast extract plus thiamine & 6.56 \\
\hline $0.1 \%$ yeast extract & 1.43 \\
\hline $0.1 \%$ yeast extract plus thiamine & 26.11 \\
\hline $\begin{array}{l}0.1 \% \text { yeast extract plus } 0.2 \% \mathrm{~N}-\mathrm{Z} \text { case } \\
\text { peptone }\end{array}$ & 1.25 \\
\hline $\begin{array}{l}0.1 \% \text { yeast extract plus } 0.2 \% \mathrm{~N}-\mathrm{Z} \text { case } \\
\text { peptone plus thiamine }\end{array}$ & 5.92 \\
\hline $\begin{array}{l}0.1 \% \text { yeast extract plus } 0.2 \% \mathrm{~N}-\mathrm{Z} \text { case } \\
\text { peptone plus } 1 \% \text { glycerol with thiamine }\end{array}$ & 1.40 \\
\hline $0.2 \% \mathrm{~N}-\mathrm{Z}$ case peptone & 0 \\
\hline $0.2 \% \mathrm{~N}-\mathrm{Z}$ case peptone plus thiamine & 0.42 \\
\hline $0.1 \% \mathrm{~N}-\mathrm{Z}$ case peptone & 0 \\
\hline $0.1 \% \mathrm{~N}-\mathrm{Z}$ case peptone plus thiamine & 0 \\
\hline
\end{tabular}

since addition of thiamine either to PG medium or to $\mathrm{CM}$ medium from which phosphate salts were omitted induced formation of siqnificant amounts of prodigiosin, these media were used in most of our experiment .

the pyrimidine moiety of thiamine 2methyl - 4- amino -5- aminomethyl pyrimidine, was about $10 \%$ as effective as the vitamin in inducing prodigiosin formation in strain 9-3-3 \{Table 3 \}.

\{ Table 3 \} Inducing of prodigiosin synthesis in $S$. marcescens strain 9-3-3 by thiamin and its moieties

\begin{tabular}{|c|c|c|}
\hline \multirow[b]{2}{*}{$\begin{array}{l}\text { tCompound } \\
\text { added to PG } \\
\text { medium }\end{array}$} & \multicolumn{2}{|c|}{ prodigiosin formation } \\
\hline & $\begin{array}{c}\mu \mathrm{g} / \mathrm{mg} \text { of } \\
\text { protein/ } \mathrm{ml}\end{array}$ & $\begin{array}{c}\text { \% formed } \\
\text { (compared to } \\
\text { thiamine ) }\end{array}$ \\
\hline None & 0.10 & 1.1 \\
\hline Thiamine .HCL & 9.42 & 100.0 \\
\hline pyrimidin moity & 1.10 & 11.7 \\
\hline Thiazole moity & 0.37 & 3.9 \\
\hline $\begin{array}{c}\text { Pyrimidin\& } \\
\text { Thiazole } \\
\text { moieties }\end{array}$ & 2.18 & 23.1 \\
\hline
\end{tabular}

The Thiazole moiety , 4- methyl 5 (ß- hydroxyelthyl)- thiazole, was evenless effective .

Addition of both moieties to PG medium gave about $25 \%$ of the response of thiamine itself . The above data suggested that the addition of thiamine enabled strain 9-3-3 to synthesize MAP .

\section{DISCUSSION:}

Thiamine induced formation of pigment in mutant strain 9-3-3 by stimulating production of MAP. spectral \& chromatographic evidence indicated that the pigment was prodigiosin. Thiamine did not cause reversion of strain 9-3-3 to a pigmented state, nor did it favor the selection of a spontaneous, pigmented mutant . when red pigmented cells of strain 9-3-3 were harvested washed, and then inoculated into fresh medium without thiamine, their ability to form prodigiosin disappeared. Thiamine also enhanced production of prodigiosin by wild - type strain nima, however strain $\mathrm{H}-262$, a single - step mutant that is phenotypically like strain 9-3-3, did not form pigment when grown in the presence of thiamine.

This was not surprising, since strain 9-3-3 is a spontaneous mutant isolated from another spontaneous mutant, strain 9-3-3 that originated from wild - type , strain 274 of $S$. marcescens . thus , strain9-3-3 arose as the result of two mutations . although both mutational events might affect biosynthesis of MAP , only one might involve thiamine. The vitamin might relieve one block, allowing synthesis of an intermediate that could be used to overcome the second block. Relief of the second block would permit biosynthesis of MAP .

Mutant strain 9-3-3 grew well an a minimal medium containing no thiamine the organism can synthesize enough of the vitamin to carry out basic metabolic reaction .

Mutant strain 9-3-3 also apparently synthesize only a limited amount of the 
pyrimidine component of the vitamin ,since additional ( amounts of this moiety do induce formation of some prodigiosin . Addition of the thiazole moiety induce formation of only a limited amount of pigment . Addition of both moieties together does not cause formation of pigment equivalent to that formed by the addition of the whole molecule, thus, the mutant evidently has a limited capacity to couple the two moieties to form thiamine . strain 9-3-3 grows well aerobically ,presumably by utilizing cytochrome enzymes .

These observations indicate that the mutant synthesizes the pyrrole groups of the porphrins found in these enzymes .

the usual path way for pyrrole biosynthesis involves $\delta$ - amino levulinic acid, but this compound is poorly incorporated into prodigiosin [ 11 ] [ 19].

this fact suggests that pyrrole groups of prodigiosin are synthesized by different path way than the pyrrole of the porphyrins. The pyrrole moieties of prodigiosin, MAP \& MBC, although they may have common early precursors [ 13 ] . our data indicate that thiamine influence synthesis of MAP, but the effect of the vitamin may be indirect and may involve some other pathway, rather than affecting synthesis of MAP directly . the vitamin dose not substitute for MAP because addition of thiamine to suspensions of cells of strain 9-3-3 .

phosphate salts inhibit biosynthesis of prodigiosin by wild-type organism[ 1] [ 9 ], biosynthesis of $\mathrm{MBC}$ in strain 9-3-3 [17 ] and biosynthesis of MAP\& MBC in other mutas [ 5 ] [ 13 ]. phosphate causes a similar inhibition of thiamine- induced pigmentation in strain 9-3-3 .

The effect of thiamine and of phosphate salts may be related and may involve a common biosynthetic step. Interestingly ,when strain 9-3-3 is grown in the absence of thiamine in media lacking phosphate salts [ 14 ] or in PG medium, it produces a purple pigment .
This pigment has different spectral characteristic than prodigiosin and is probably identical to the dipyrrolyl dipyrromethene analogue of prodigiosin recently reported [ 15 ].

\section{CONCLUSION}

1. Serratia marcescens produces a red pigment when grown aerobically at temperatures below $37 \mathrm{C}$.

2. Mutant strain 9-3-3 is blocked in synthesis of MAP but can synthesis MBC.

3. When thiamine is added to the growth medium, strain 9-3-3 produces a red pigment.

4. Thiamine is probably involved in the regulation of the biosynthesis of MAP.

\section{REFERENCES}

1. Abdel hamid J;Ahmed, S;Philippe,C.2002 " Characterization of Serracin p a phage-tail like becteriocin" J.appl.envirom .microbiol. 68:5704-5710.

2. Beatriz,M;

Sira,N;Maria,P;Marta,V;Marc,M;Joan,G;R icardo,P. .2000 " prodigiosin from the supernatant of Serratia marcescens induced apoptosis inhaematopietic cancer cell line" British journal of pharmacology . 131:585-593.

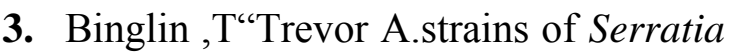
spp" J.appl.envirom.microbiol.sep. 2006.

4. Boger,D;Patel,M; 1988 "Total synthesis of prodigiosin \& deswethoxy prodigiosin" J.org.chem .53:1405-1415..

5. Bunting,M; .1940 "Adescrpition of some colour variants produced by Serratia marcescens strain 274" J.Bactriol.40:5768.

6. Gerber,N; 1975 "Prodigiosin- like pigment" Crc.crti.rev. microbial 3:469485.

7. Han,S; Lee,C. 1998 "Prodigiosin isolated from Serratia marcescens". appl microbial.biotechnol 20:1-13..

8. Jun,R; 2006 "Biosynthesis prodigiosin in Serratia marcescens" J.med. microbial.apr. 
9. Kobayashi,N; 1991\& Ichikawv“ Prodigiosin-Localising crude Vesicle which is protease and nuclease in Serratia marcescens" J.immunol .35:607-614..

10. lowry,O;Rosebrough,N; 1951 "Protein measurement with folin phenol reagent" j.biol.chem.193:265-275..

11. Marks,G;Bogorad,1; 1960 "Studieson the biosynthesis of prodigiosin in Serratia marcescens" Acad.sic.46:25-28.

12. Matsuyama,T;Fujita,M; 1986. "Extracellular vesicle formation a production by Serratia marcescens"J. Gener. 91:865-875.

13. Mortellaro,A;Golay ,J 1999 "prodigiosin synthesis in Serratia marcescens" J.immunol. 162: 7102-7109..

14. Sandhiya,T;Sugitha, C; Balachandar,D . 2005 "Endophytic colonization and in planta nitrogen by Serratia sp "J.exp. biol. 9.
15. Stock,I;Grueger,T; .2003 "The natural susceptibility of 77 strains of Serratia marcescens \&41strains of Serratia "J. bact. 7:29-37.

16. Wasserman ,H;Mckeon J;smith,l; 1966. "Studies of prodigiosin and the biopyrrol precursor "Tetrahedron suppl. (8)2:647-662.

17. Williams, R;Slater ,H; 2004. "Species and strain dependent genome context varation "J. microbial. 11.

18. WillimR;green,J,Rapport,D ; .1956 "studies on pigmentation of Serratia marcescens " I spectral \&paper chromatographic properties of prodigiosin" J.bact. 71:115-120.

19. Yoshida ,J ; Nisio ,M .2000 "Biosnthesis of prodigiosin from Serratia sp " J. bact 62:1043-1053.

\section{حث الثايمين على تكوين صبغة البرودبجيوسين عن طريق شطر اصرة احادي البرولين}
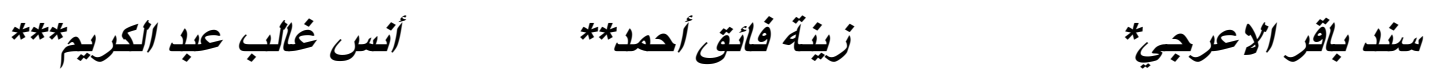

$$
\begin{aligned}
& \text { * أستاذ مساعد/كلية التقنيات الطبية و الصحية }
\end{aligned}
$$

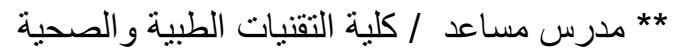

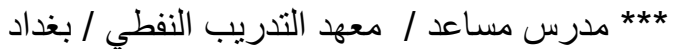

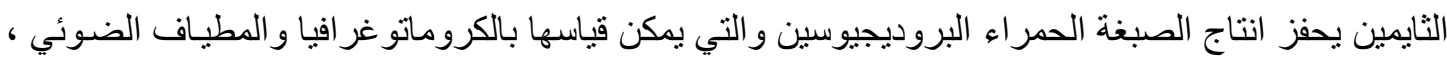

الخلاصة :

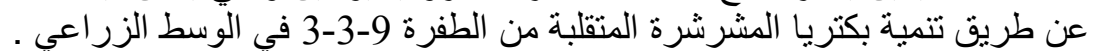

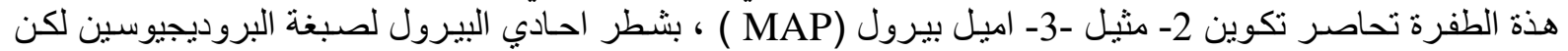
يكدس 4- ميثوكسي -2، 2- ثنائي الييرول -5- كاربوكسيلديهايد ( MBC ) ويمكن دمـج هذا المركب مـع (MAP )

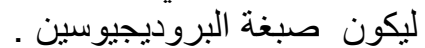

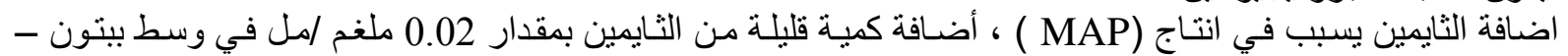

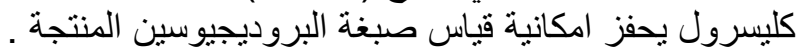

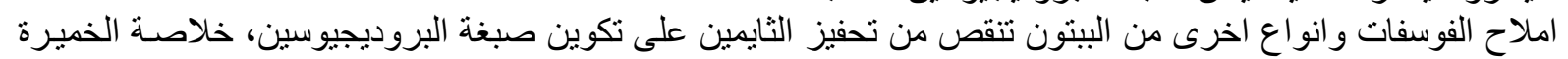

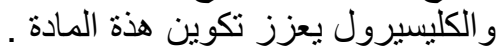

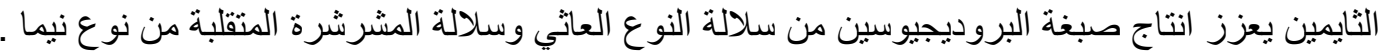

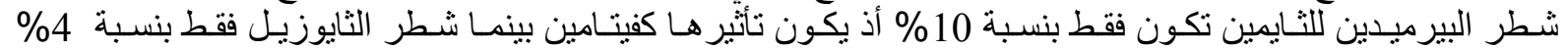

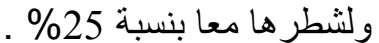

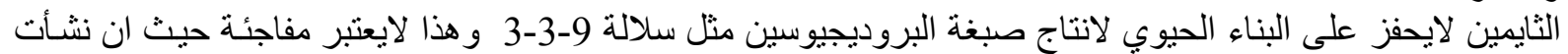

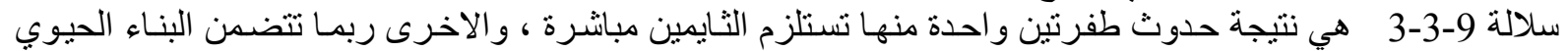

